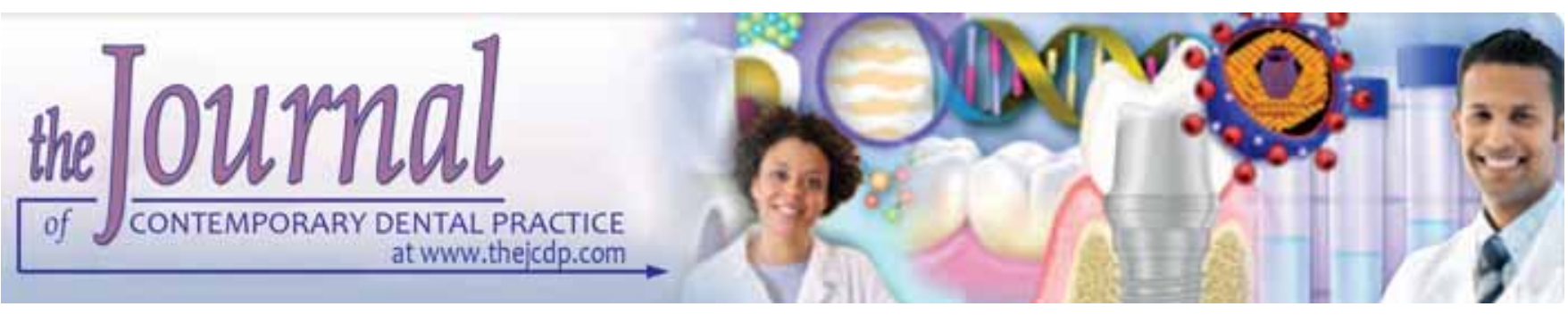

\title{
Effect of Two Types of Composite Fibers on Fracture Resistance of Endodontically Treated Maxillary Premolars: An in vitro Study
}

\author{
Parnian Alizadeh Oskoee, Mohammad Esmaeel Ebrahimi Chaharom, Soodabeh Kimyai \\ Jafar Sadjadi Oskoee, Sahar Varasteh
}

\section{ABSTRACT}

Aim: The aim of the present study was to evaluate the effect of the use of composite fibers (glass fiber and polyethylene fiber) at the gingival third of mesio-occlusodistal (MOD) cavities on the fracture resistance of endodontically treated premolars.

Materials and methods: A total of 45 extracted premolars underwent endodontic treatment. MOD cavities, $2.5 \pm 0.2 \mathrm{~mm}$ thick at the buccal and lingual heights of contour, were prepared, with the gingival cavosurface margin $1.5 \mathrm{~mm}$ coronal to the cementoenamel junction. Then the teeth were randomly divided into three groups. In group 1, the cavities were restored with Z250 composite resin without the use of any fibers. In groups 2 and 3 , the teeth were restored in the same manner as that in group 1 after placement of glass fiber and polyethylene fiber at the gingival third of the cavities, respectively. Subsequent to thermocycling, fracture resistance of the specimens was measured in Newton $(\mathrm{N})$.

Statistical analysis: Data were analyzed with one-way ANOVA and a post hoc Tukey test at a significance level of $p<0.05$.

Results: There were significant differences in the means of fracture resistance values between the three groups $(p=0.001)$. Statistically significant differences were observed in the fracture resistance between group 2 and groups 1 and $3(p<0.05)$. However, the differences between groups 1 and 3 were not significant $(p=0.25)$.

Conclusion: The type of fiber influenced the fracture resistance of endodontically treated human premolars.

Clinical significance: Using glass and/or polyethylene fibers in the gingival third of composite restorations leads to different results in fracture resistance of endodontically treated maxillary premolars.

Keywords: Fiber-reinforced composite, Fracture resistance, Glass fiber, Polyethylene fiber, Laboratory research.

How to cite this article: Oskoee PA, Chaharom MEE, Kimyai S, Oskoee JS, Varasteh S. Effect of Two Types of Composite Fibers on Fracture Resistance of Endodontically Treated Maxillary Premolars: An in vitro Study. J Contemp Dent Pract 2011;12(1):30-34
Source of support: This research project was supported financially by the Vice Chancellor for Research at Tabriz University of Medical Sciences.

Conflict of interest: None declared

\section{INTRODUCTION}

Restoration of endodontically treated teeth plays an important role in the success of root canal treatment. ${ }^{1}$ Endodontically treated teeth are more susceptible to fracture due to greater cavity depth and loss of more dentin. ${ }^{2}$ Therefore, intracoronal reinforcement of such teeth, especially in posterior regions, is of utmost importance in providing fracture resistance. ${ }^{1}$ Maxillary premolars have a unique position among the posterior teeth: On the one hand they play an important role in the esthetics of a beautiful smile; on the other hand, they are subjected to a combination of compressive and shearing forces as a result of their functional role in mastication. Therefore, there is a need for high-strength tooth-colored restorations in these teeth when they are damaged by dental diseases. According to previous studies, crowns, cast onlays, amalgam onlays or composite resins can be used to restore endodontically treated teeth. ${ }^{2}$ Given the recent advances in adhesive technology and introduction of new generations of composite resins, conservative direct restorations with highly-acceptable esthetics have become possible. ${ }^{2}$ Hernandez et al showed that fracture resistance of endodontically treated premolars increases with the use of dentin bonding systems with composite resins. ${ }^{3}$ Nevertheless, polymerization shrinkage and the concomitant stresses upon the restoration-tooth interface have an influence upon the final outcome of extensive composite resin restorations. ${ }^{1} \mathrm{~A}$ proposed procedure to resolve the 
above-mentioned problem is the use of an intermediary resin with low viscosity and modulus of elasticity between the bonding agent and the composite resin, which serves as an elastic buffer. ${ }^{4,5}$ One of the materials which can be used to this end is flowable composite. Although the use of flowable composite resin alone does not increase fracture resistance of endodontically treated teeth with MOD cavities, incorporation of polyethylene fibers into flowable composite resin can increase fracture resistance of these teeth. ${ }^{2}$ In addition, this combination of materials functions as a stress absorber due to its low modulus of elasticity. ${ }^{1}$ According to a previous study, fiber-reinforced composite resins have sufficient flexural modulus and strength to function successfully in the oral cavity. ${ }^{6}$

At present, various kinds of fibers are available to reinforce composites, with different physical and mechanical properties. $^{7}$ Physical and mechanical properties and the reinforcing effect of fibers are under the influence of various factors, of which the fiber type can be mentioned. ${ }^{8}$ Several studies have demonstrated differing behaviors of fibers in increasing fracture resistance of endodontically treated teeth. ${ }^{1,2,9}$ Considering structural and physical differences of fibers and also the fact that no studies have ever compared the efficacy of various composite fibers with composite resin restorations in increasing fracture resistance of endodontically treated premolars, the aim of the present study was to evaluate the effect of two different types of composite fibers (glass fiber and polyethylene fiber) on the fracture resistance of endodontically treated maxillary premolars.

\section{MATERIALS AND METHODS}

In this in vitro study, 45 sound human single-rooted maxillary premolars, extracted for orthodontic reasons, were used. The teeth had almost similar sizes and dimensions. The teeth were devoid of cracks and fractures when evaluated under transillumination. The teeth were stored in $0.5 \%$ chloramine T trihydrate solution (Merck, Munich, Germany) at $4^{\circ} \mathrm{C}$ until used for the purpose of the study. Tooth surfaces were cleaned with hand instruments; then access cavities were prepared using a coarse tapered flat-end bur (MANI, Nakaakutsu, Japan) in a high-speed handpiece. A \# $10 \mathrm{~K}$ type file (Dentsply Maillefer, Simfra, Switzerland) was inserted into the canal so that the tip of the file was visible at the apical foramen. A millimeter was subtracted from this length to determine the working length (WL). K-files were used up to \# 30 to prepare the canals by the step-back technique. Flaring of the canals was carried out by \# 3, \# 2, and \# 1 Gates Glidden drills (MANI, Nakaakutsu, Japan). After each instrumentation step, $5.25 \% \mathrm{NaOCl}$ was used to irrigate the canals. Subsequent to drying out the canals with paper points (Diadent Group, Chongju, Korea), they were obturated with gutta-percha (Diadent Group, Chongju, Korea) and AH 26 sealer (Dentsply, Konstanz, Germany) using a lateral condensation technique. Subsequent to obturation all the teeth were further examined regarding craze lines, cracks and fractures using transillumination technique. Furthermore, radiographic control of obturation was performed in order to exclude any teeth with nonhomogeneous root canal filling and voids. Thereafter, MOD cavities, to a standard design, were prepared so that the wall thickness from the buccal and lingual heights of contour was $2.5 \pm 0.2 \mathrm{~mm}$ and the gingival floor was $1.5 \mathrm{~mm}$ coronal to cementoenamel junction (CEJ). The teeth were embedded in self-cured acrylic resin up to CEJ and were randomly divided into three groups of 15 teeth each.

The teeth in group 1 (the group without fiber) were etched for 15 seconds with 35\% phosphoric acid (Scotchbond Etchant, 3M-ESPE, St Paul, MN, USA) using the total etch technique (simultaneous etching of the enamel and dentin). Then tooth surfaces were rinsed for10 seconds and dried with an air spray for 1 to 2 seconds at a distance of $2 \mathrm{~mm}$ from the tooth surface so that the wet and shiny appearance of dentin was preserved; the air spray was not contaminated with water or oil. Single Bond adhesive (3MESPE, St Paul, MN, USA) was applied in two coats according to the manufacturer's instructions and light-cured for 10 seconds using an Astralis 7 light-curing unit (Ivoclar Vivadent, Liechtenstein, Austria) set at the low-power program at a light intensity of $400 \mathrm{~mW} / \mathrm{cm}^{2}$. Subsequent to placement of a metallic matrix band (Tofflemire Matrix, Arzier, Switzerland) around the teeth, the cavities were restored with Filtek Z250 (3M-ESPE, St Paul, MN, USA) composite resin using an incremental technique. In this, each $1.5 \mathrm{~mm}$ incremental layer was light-cured before placing the next layer. The tip of the instrument was placed from the occlusal aspect, touching the cusps. The restorations were cured using pulse program mode in which the light intensity was $150 \mathrm{~mW} / \mathrm{cm}^{2}$ at first, increasing to $400 \mathrm{~mW} / \mathrm{cm}^{2}$ in 15 seconds and fluctuating between $400 \mathrm{~mW} / \mathrm{cm}^{2}$ and $750 \mathrm{~mW} / \mathrm{cm}^{2}$ every two seconds until the total time added up to 40 seconds. After completing the restoration procedure and removing the matrix band, curing was repeated from mesial and distal aspects for 40 seconds each.

In groups 2 and 3 (glass fiber and polyethylene fiber groups, respectively) the same procedures were repeated except for the fact that after etching and applying the bonding agent, the cavity floor was covered with a $1 \mathrm{~mm}$ layer of Filtek Flow composite resin (3M-ESPE, St Paul, MN, USA). 'Prior to the light-curing procedure, preimpregnated glass fiber (Interlig, Angelus, Londrina PR, Brazil) and fiber-braided preimpregnated polyethylene fiber 
(NSI, Hornsby, Australia) with thicknesses of $2 \mathrm{~mm}$ and $0.3 \mathrm{~mm}$, respectively, were placed from the gingival third of the buccal aspect to the gingival third of the gingival aspect of the lingual wall on the cavity floor and inside the flowable composite (Fig. 1). Then the pulse program of Astralis 7 light-curing unit was used to cure the materials for 40 seconds. The remainder of the cavity was restored similar to the procedure in group 1 . All the specimens were subsequently subjected to a thermocycling procedure, which consisted of 500 cycles at $5^{\circ} \mathrm{C} \pm 2^{\circ} \mathrm{C} / 55^{\circ} \mathrm{C} \pm 2^{\circ} \mathrm{C}$ with a dwell time of 30 seconds and a transfer time of 5 seconds. Then the specimens were incubated at $37^{\circ} \mathrm{C}$ and $100 \%$ relative humidity for 24 hours. All the endodontic and restorative procedures were carried out by one operator.

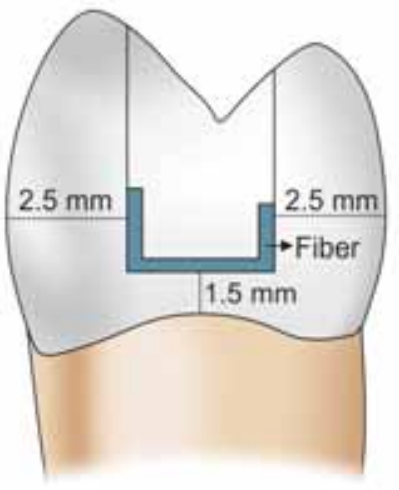

Fig. 1: Position of the fibers

The specimens were embedded in cold-cured acrylic resin up to $1.5 \mathrm{~mm}$ apical to CEJ and subjected to a compressive force at a crosshead speed of $0.5 \mathrm{~mm} / \mathrm{min}$ in a test machine (Hounsfield Test Equipment, model H5K-S, England). The force was applied with a steel ball with a tip diameter of $5 \mathrm{~mm} .{ }^{9}$ In all the specimens, the force was applied to the occlusal surface of the restoration at 90 degrees with the force-applying apparatus parallel to the long axis of the tooth, touching the buccal and lingual cusps. The force applied was measured in Newton at fracture. Fracture patterns were evaluated by determining favorable and unfavorable fracture modes. Favorable fractures were located coronal to CEJ and unfavorable ones were apical to CEJ.

Fracture resistance data was analyzed by one-way ANOVA and a post hoc Tukey test at a significance level of $\mathrm{p}<0.05$ after means and standard deviations were calculated, using SPSS 16 software package. Chi-square test was used for comparison of fracture mode frequencies in the study groups.

\section{RESULTS}

Table 1 contains the mean applied force to fracture in Newton and its standard deviation (SD) for the groups tested.
The results of one-way ANOVA showed that there were significant differences in the mean force to fracture between the three experimental groups $(\mathrm{p}=0.001)$. According to the results of Tukey test there were statistically significant differences in fracture resistance between group 2 and groups 1 and 3 ( $p=0.03$ and $p<0.001$ respectively). However, the differences between groups 1 and 3 were not significant $(p=0.25)$. Moreover, based on the Chi-square test there was not any significant association between the study groups and the fracture patterns $\left(\chi^{2}=0.25, \mathrm{df}=2\right.$, $p=0.87$ ). Evaluation of fracture patterns revealed that most of the fractures in the three groups were unfavorable and apical to CEJ (Table 2).

$\begin{aligned} & \text { Table 1: The means and standard deviations (SD) of fracture } \\
& \text { resistance in Newton in the study groups }\end{aligned}$
\begin{tabular}{lrrrr} 
Groups & $n$ & Mean $\pm S D(N)$ & Minimum & Maximum \\
\hline $\begin{array}{l}\text { Group 1 } \\
\text { (without fiber) }\end{array}$ & 15 & $622.07 \pm 67.18$ & 498.00 & 720.00 \\
$\begin{array}{l}\text { Group 2 } \\
\text { (glass fiber) }\end{array}$ & 15 & $507.77 \pm 100.63$ & 355.00 & 650.00 \\
$\begin{array}{l}\text { Group 3 } \\
\text { (polyethylene fiber) }\end{array}$ & 15 & $694.60 \pm 157.56$ & 466.00 & 997.00 \\
\hline
\end{tabular}

Table 2: Frequencies of fracture patterns in the study groups

\begin{tabular}{lcc}
\hline Groups & $\begin{array}{c}\text { Favorable } \\
\text { fracture }\end{array}$ & $\begin{array}{c}\text { Unfavorable } \\
\text { fracture }\end{array}$ \\
\hline Group 1 (without fiber) & $3(20 \%)$ & $12(80 \%)$ \\
Group 2 (glass fiber) & $4(26.7 \%)$ & $11(73.3 \%)$ \\
Group 3 (polyethylene fiber) & $3(20 \%)$ & $12(80 \%)$ \\
\hline
\end{tabular}

\section{DISCUSSION}

In restoration of endodontically treated teeth, the key factor for treatment success is selection of the best material and technique based on the functional needs and the amount of remaining tooth structure. Several materials and techniques have been proposed to increase the rate of success in restoring teeth with extensive loss of tooth structures. ${ }^{10,11}$ Introduction of fiber-reinforced composite technology has increased the use of composite materials in large cavities. ${ }^{2}$ Considering the contradictory results about the use of composite fibers at cavity floors of endodontically treated teeth in two previous studies, ${ }^{1,9}$ the present study made an attempt to evaluate the effect of composite fibers (glass and polyethylene fibers) at the gingival third of MOD composite resin restorations on fracture resistance of endodontically treated premolars.

Based on the results of this study, the highest and lowest fracture resistance means were observed in group 3 (polyethylene fiber) and group 2 (glass fiber), respectively, with statistically significant differences in fracture resistance 
between glass fiber group and the two other groups (polyethylene fiber and no fiber groups). Several studies have shown that the use of polyethylene fibers, with high modulus of elasticity and favorable flexural strength, along with flowable composites under composite restorations increases fracture resistance due to its modifying effect on interstitial stress at tooth-restoration interface. ${ }^{2,12,13}$ It has been reported that polyethylene fibers increase the impact strength, modulus of elasticity and flexural strength of composite resins. ${ }^{14}$ It should be pointed out that glass fibers contain interlaced glass and can increase the impact strength of composites. ${ }^{14}$ Kolbeck et al even reported that the reinforcing effect of glass fibers is greater than that of polyethylene fibers; of course, they had used untreated polyethylene fibers in their study and attributed the results of the study to the absence of proper adhesion between polyethylene fibers and the resin matrix. ${ }^{15}$ From a chemical point of view, glass is an amorphous material which consists of bonded tetrahydrate silica in a random lattice; therefore, glass fibers have varying physicochemical properties, ${ }^{7}$ differentiating them from organic fibers such as polyethylene fibers. Since the polyethylene fiber used in the present study was of the preimpregnated type, it is probable that the above-mentioned differences might have influenced the properties of the surface composite adhering to glass fiber and polyethylene fiber, resulting in differences in the fracture resistance between the two groups. If the adhesion between the composite and fibers is not favorable (the same as what is expected in the glass fiber group), it is expected that fiber will act as an inclusion body, resulting in weakening of the resin structure rather than in strengthening it. ${ }^{16}$ The other finding of the present study was that there were no differences in fracture resistance between polyethylene fiber and no fiber groups. However, in some studies the use of composite fibers along with composite restorations has significantly increased fracture resistance through an increase in the flexural strength of the whole structure. ${ }^{2,12,14,17-19}$ It appears apart from physical factors (fiber type and polymer matrix), fiber surface treatment, adhesion of fiber to polymer matrix, ${ }^{20}$ fiber orientation, and fiber placement technique influence the mechanical properties of fiber-reinforced composite resins. ${ }^{8}$ According to the results of study carried out by Oskoee et $\mathrm{al},{ }^{9}$ fracture resistance decreases with an increase in the distance between the fiber and the point of force application, which is explained by the increase in the length of working arm, based on the law of levers. ${ }^{1,9}$ Garoushi et al in their study referred to the effect of distance between the fiber and point of force application on fracture resistance. ${ }^{17}$

In this study, apart from the effect of physical and chemical differences on the performance of two types of fibers, ${ }^{7}$ it seems the distance from the point of force application and the working arm length can also influence the final results of fracture resistance tests.

In the present study, similar to a previous study, ${ }^{9}$ the majority of fractures were unfavorable. However, Fennis et al showed that in cusp-covering and cusp-replacing procedures composite restorations reinforcing composite resin with glass fiber has a beneficial effect on failure mode. $^{21}$

Finally, it should be pointed out that in the present in vitro study, a static force was used to evaluate fracture resistance. Although the results might be useful in predicting clinical function, it is suggested that the effect of other factors, such as fiber type and the properties of the composite covering the surface of fibers in difference positions and distances relative to the point of force application, be evaluated in conditions similar to the oral cavity conditions in future studies. This recommendation is justified considering the importance of fatigue stress in intraoral situations and the role of the properties of the composite covering the fiber surface in the physical properties of fiberreinforced composites and the resistance of the final restoration. ${ }^{22,23}$ Moreover, the evaluation of stress distribution at tooth cusp and also cuspal deflection through different methods, such as finite element analysis, are suggested in future researches. Finite element analysis helps to evaluate the effect of single and combined factors on tooth-restoration complex. Furthermore, it will help better to understand the nature of stress and strain distributions.

\section{CONCLUSION}

Considering the limitations of this in vitro study, it can be concluded that using glass and/or polyethylene fibers in the gingival third of composite restorations leads to different results in fracture resistance of endodontically treated maxillary premolars.

\section{CLINICAL SIGNIFICANCES}

Using glass and/or polyethylene fibers in the gingival third of composite restorations leads to different results in fracture resistance of endodontically treated maxillary premolars.

\section{ACKNOWLEDGMENTS}

The authors wish to thank the Vice Chancellor for Research at Tabriz University of Medical Sciences for financial support. The authors also thank Dr M Abdolrahimi (DDS) who edited the English manuscript of this article.

\section{REFERENCES}

1. Belli S, Erdemir A, Yildirim C. Reinforcement effect of polyethylene fibre in root-filled teeth: Comparison of two restoration techniques. Int Endod J 2006;39:136-42. 
2. Belli S, Erdemir A, Ozcopur M, Eskitascioglu G. The effect of fibre insertion on fracture resistance of root filled molar teeth with MOD preparations restored with composite. Int Endod J 2005;38:73-80.

3. Hernandez R, Bader S, Boston D, Trope M. Resistance to fracture of endodontically treated premolars restored with new generation dentine bonding systems. Int Endod J 1994;27:281-84.

4. Kemp-Scholte CM, Davidson CL. Marginal integrity related to bond strength and strain capacity of composite resin restorative systems. J Prosthet Dent 1990;64:658-64.

5. Van Meerbeek B, Lambrechts P, Inokoshi S, Braem M, Vanherle G. Factors affecting adhesion to mineralized tissues. Oper Dent 1992;5:111-24

6. Vallittu PK. The effect of glass fiber reinforcement on the fracture resistance of a provisional fixed partial denture. J Prosthet Dent 1998;79:125-30.

7. Ellakwa AE, Shortall AC, Marquis PM. Influence of fiber type and wetting agent on the flexural properties of an indirect fiber reinforced composite. J Prosthet Dent 2002;88:485-90.

8. Ellakwa AE, Shortall AC, Shehata MK, Marquis PM. The influence of fibre placement and position on the efficiency of reinforcement of fibre reinforced composite bridgework. J Oral Rehabil 2001;28:785-91.

9. Oskoee PA, Ajami AA, Navimipour EJ, Oskoee SS, Sadjadi J. The effect of three composite fiber insertion techniques on fracture resistance of root-filled teeth. J Endod 2009;35:413-16.

10. Panitvisai $\mathrm{P}$, Messer $\mathrm{HH}$. Cuspal deflection in molars in relation to endodontic and restorative procedures. J Endod 1995;21:57-61.

11. Hürmüzlü F, Kiremitçi A, Serper A, Altundasar E, Siso SH. Fracture resistance of endodontically treated premolars restored with ormocer and packable composite. J Endod 2003;29:838-40.

12. Eskitascioğlu G, Belli S, Kalkan M. Evaluation of two post core systems using two different methods (fracture strength test and a finite elemental stress analysis). J Endod 2002;28:629-33.

13. Meiers JC, Kazemi RB, Donadio M. The influence of fiber reinforcement of composites on shear bond strengths to enamel. J Prosthet Dent 2003;89:388-93.

14. Arhun N, Arman A. Fiber-reinforced technology in multidisciplinary chairside approaches. Indian J Dent Res 2008;19:272-77.

15. Kolbeck C, Rosentritt M, Behr M, Lang R, Handel G. In vitro study of fracture strength and marginal adaptation of polyethylene fibre-reinforced composite versus glass fibre-reinforced composite fixed partial dentures. J Oral Rehabil 2002;29:668-74.

16. Vallittu PK. Comparison of two different silane compounds used for improving adhesion between fibres and acrylic denture base material. J Oral Rehabil 1993;20:533-39.
17. Garoushi S, Lassila LV, Tezvergil A, Vallittu PK. Load bearing capacity of fibre-reinforced and particulate filler composite resin combination. J Dent 2006;34:179-84.

18. Powell DB, Nicholls JI, Yuodelis RA, Strygler H. A comparison of wire- and Kevlar-reinforced provisional restorations. Int J Prosthodont 1994;7:81-89.

19. Ramos V Jr, Runyan DA, Christensen LC. The effect of plasmatreated polyethylene fiber on the fracture strength of polymethyl methacrylate. J Prosthet Dent 1996;76:94-96.

20. Lassila LV, Nohrström T, Vallittu PK. The influence of shortterm water storage on the flexural properties of unidirectional glass fiber-reinforced composites. Biomaterials 2002;23: 2221-29.

21. Fennis WM, Tezvergil A, Kuijs RH, Lassila LV, Kreulen CM, Creugers NH, Vallittu PK. In vitro fracture resistance of fiber reinforced cusp-replacing composite restorations. Dent Mater 2005;21:565-72.

22. Ellakwa A, Shortall A, Shehata M, Marquis P. Influence of veneering composite composition on the efficacy of fiberreinforced restorations (FRR). Oper Dent 2001;26:467-75.

23. Ellakwa AE, Shortall AC, Shehata MK, Marquis PM. Influence of bonding agent composition on flexural properties of an ultrahigh molecular weight polyethylene fiber-reinforced composite. Oper Dent 2002;27:184-91.

\section{ABOUT THE AUTHORS \\ Parnian Alizadeh Oskoee}

Associate Professor, Department of Operative Dentistry, School of Dentistry, Iran

\section{Mohammad Esmaeel Ebrahimi Chaharom}

Assistant Professor, Department of Operative Dentistry, School of Dentistry, Iran

\section{Soodabeh Kimyai (Corresponding Author)}

Associate Professor, Department of Operative Dentistry, School of Dentistry, Tabriz University of Medical Sciences Gholghasht Street, Zip: 5166614713, Tabriz, Iran, e-mail: kimyais@tbzmed.ac.ir

\section{Jafar Sadjadi Oskoee}

Assistant Professor, Department of Community Dentistry, School of Dentistry, Iran

\section{Sahar Varasteh}

DDS, Department of Operative Dentistry, School of Dentistry, Iran 